KINH TẾ VIỆT NAM: GIẢI PHÁP "VƯợT ĐÁY” VÀ TĂNG TRƯởNG BỀN VŨ̃NG

VIETNAM ECONOMY: SOLUTIONS FOR ESCAPING DEPRESSION AND TOWARDS A SUSTAINABLE DEVELOPMENT

\author{
Nguyễn Chí Hải \\ Trường ĐH Kinh tế - Luật, ĐHQG - HCM - hainc@uel.edu.vn \\ Nguyễn Thùy Dương \\ Trường Đại học Kinh tế TP. HCM
}

(Bài nhận ngày 20 tháng 01 năm 2015, hoàn chỉnh sửa chũa ngày 26 tháng 03 năm 2015)

\title{
TÓM TÁ́T
}

Nội dung bài viết nhằm nhận diện và đánh giá căn nguyên suy giảm tăng truởng của nền kinh tế Việt Nam giai đoạn 2011 - 2014. Kết quả nghiên cưu chỉ ra rằng, bên cạnh nhũng nguyên nhân nội tại của mô hình tăng trưởng, điểm nghẽn hiện tại của nền kinh tế chính là sụ lạc hậu về trình độ công nghệ và năng suất thấp. Bài viết cũng khuyến nghị các giải pháp để nền kinh tế Việt Nam "vuợt đáy" suy giảm và tăng trưởng bền vũng.

Tù khóa: Chu kỳ kinh tế, đáy của chu kỳ kinh tế, năng suất, khoa học công nghệ, phát triển kinh tế bền vũng.

\section{ABSTRACT}

This study aims to identify and evaluate the reason for the decline of Vietnam's economic growth in the period 2011 -2014. The results indicate that, in addition to endogenous problems of the growth model, obsolete technology and low productivity are the main factors causing the decline. The study also offers some suggestions for Vietnam to get out of the economicdepression and reach a sustainable development.

Key words: Economic cycle, economic depression, productivity, science and technology, sustainable economic development.

\section{GIỚI THIẸU}

"Kinh tế Việt Nam đã đến đáy?" là chủ đề của một cuộc Tọa đàm khoa học được tổ chức tại TP.HCM vào cuối tháng 11 năm 2014 với sự góp mặt của một số chuyên gia kinh tế, giảng viên kinh tế ở Hà Nội và TP.Hồ Chí Minh. Xuất phát từ thực tiễn nền kinh tế Việt
Nam hiện nay, để trả lời câu hỏi: Kinh tế Việt Nam đã thoát đáy hay chưa? Cuộc tọa đàm "nóng" lên với câu hỏi tưởng chừng như đơn giản: Chu kỳ kinh tế là gì? Các tiêu chí đánh giá giai đoạn "suy giảm" của chu kỳ kinh tế? Thực ra đây cũng là chủ đề tranh luận giữa các nhà kinh tế theo trường phái nội sinh và ngoại 
sinh trong việc giải thích nguyên nhân của chu kỳ kinh tế.

Những kết quả khá lạc quan về sự hồi phục và ổn định vĩ mô của nền kinh tế Việt Nam năm 2014, cùng với những thành công mới trong nhận thức và thực tiễn điều hành kinh tế vĩ mô của Chính phủ, cho phép chúng ta nhận diện rõ hơn, có trọng tâm hơn về các điểm nghẽn, bất cập cốt tử trong nền kinh tế, để có những giải pháp phù hợp nhằm đưa nền kinh tế "vượt đáy" và tăng trưởng bền vững. Mục tiêu tổng quát của nền kinh tế Việt Nam năm 2015 đã được Chính phủ xác định là: “Tăng cường ổn định kinh tế vĩ mô. Đẩy mạnh thực hiện các đột phá chiến lược, tái cơ cấu kinh tế gắn với chuyển đổi mô hình tăng trưởng, nâng cao năng suất, hiệu quả và năng lực cạnh tranh, phấn đấu tăng trưởng kinh tế cao hơn và vững chắc hơn năm 2014” (Nguyễn Tấn Dũng, 2014). Thực hiện mục tiêu tổng quát này, năm 2015 sẽ là năm bản lề để nền kinh tế Việt Nam bước vào giai đoạn phát triển mới, với mục tiêu vừa đạt tốc độ tăng trưởng cao, vừa đảm bảo phát triển bền vững. Theo chúng tôi, mục tiêu tổng quát trên hoàn toàn có thể khả thi và nền kinh tế Việt Nam có cơ hội tạo ra bước đột phá mới trong năm 2015 và các năm tiếp theo, nếu nhận diện đúng căn nguyên của tình trạng suy giảm tăng trưởng kinh tế và có những giải pháp phù hợp.

Bài viết này, tác giả muốn thông qua việc trả lời câu hỏi trên, để đưa ra một cách tiếp cận về phát triển kinh tế Việt Nam hiện nay, đó là phải coi yếu tố năng suất (Productivity) là yếu tố có vai trò quyết định đối với năng lực cạnh tranh (NLCT) và tăng trưởng bền vững. Phát triển khoa học công nghệ (KHCN) chính là chìa khóa để nâng cao hiệu quả của nền kinh tế, hướng đến mục tiêu phát triển nhanh, bền vững của nền kinh tế Việt Nam trong thời gian tới.

\section{CƠ SỞ KHOA HOC VỀ CHU KỲ KINH TẾ VÀ VẬN DỤNG VÀO ĐIỀU KIỆN KINH TẾ VIẸT NAM}

Trong nền kinh tế thị trường, sự thay đổi của sản lượng, giá cả, lãi suất và thất nghiệp tạo nên chu kỳ kinh doanh. Lý thuyết chu kỳ kinh tế hay còn gọi là chu kỳ kinh doanh (Business Cycle) là một trong những lý thuyết cơ bản trong kinh tế vĩ mô, song cũng là lý thuyết gây nhiều bàn luận trong giới kinh tế học về cách giải thích các dao động của chu kỳ kinh tế. Chu kỳ kinh tế thường được hiểu là "một sự dao động của tổng sản phẩm quốc dân, của thu nhập và việc làm, thường kéo dài từ 2 đến 10 năm, được đánh dấu bằng một sự mở rộng hay thu hẹp trên quy mô lớn trên hầu hết các khu vực của nền kinh tế" (Paul $\mathrm{A}$. Samuelson - William D.Nordhaus; 2007; Trang 347). Cũng có thể diễn đạt ngắn gọn hơn, chu kỳ kinh tế là sự dao động của sản lượng thực tế xoay quanh "trục" sản lượng tiềm năng. Sự biến động của GDP thực tế trong một chu kỳ kinh tế thường theo thứ tự ba pha lần lượt là suy thoái, phục hồi và hưng thịnh (Hình 1).

Theo các nhà kinh tế, giai đoạn suy thoái trong một chu kỳ kinh tế là khi GDP của nền kinh tế suy giảm trong một thời gian nhất định. Các nhà kinh tế học cũng chỉ ra rằng dấu hiệu rõ ràng cho sự suy thoái của nền kinh tế là khi GDP thực tế tăng trưởng âm trong 2 quý liên tiếp. Theo đó, “đáy và đỉnh" của một chu kỳ kinh tế chỉ được nhận diện khi "nền kinh tế đã sang pha tiếp theo sau điểm ngoặt với dấu hiệu là tốc độ tăng trưởng GDP thực tế đổi chiều giữa mức âm và mức dương" (Chu kỳ kinh tế). 


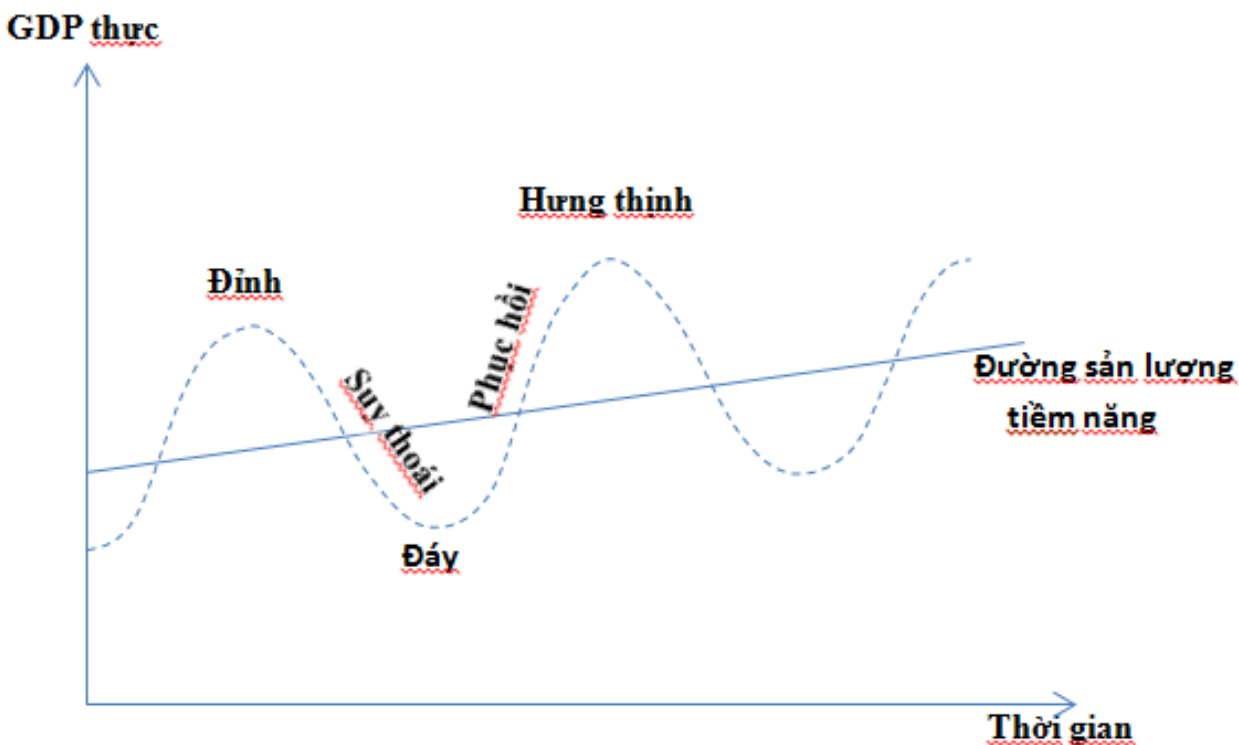

Hình 1. Chu kỳ kinh tế

Tuy nhiên, đối với các nước đang phát triển hiện nay, việc nhận diện một chu kỳ kinh tế cũng trở nên khá phức tạp, do chu kỳ kinh tế diễn ra dường như không mang tính quy luật. Nếu như căn cứ vào sự tăng trưởng âm của GDP thực tế, thì có nhiều quốc gia đang phát triển có chu kỳ kinh doanh kéo dài hàng chục năm, vì không có tăng trưởng âm. Ở các quốc gia Đông Nam Á từ sau khủng hoảng kinh tế 1997 - 1998 đến nay, chưa thấy có tăng trưởng âm trong đại đa số các quốc gia khu vực; còn ở Việt Nam, từ khi bắt đầu sử dụng cách tính GDP, chưa có năm nào tăng trưởng âm. Thực tế này chỉ ra rằng, đối với các nền kinh tế đang phát triển, giai đoạn suy thoái có thế vẫn ở mức dương nhưng GDP thực tế tăng trưởng chậm lại và giảm trong thời gian khá dài. Thêm vào đó, dấu hiệu rõ ràng về tình trạng suy thoái kinh tế còn thể hiện khá rõ theo các tiêu chí sau:

- Tiêu dùng giảm mạnh, hàng tồn kho tăng lên.
- Cầu về lao động giảm, thất nghiệp tăng ở mức cao.

- Lạm phát có xu hướng chậm lại do chi tiêu về đầu tư giảm, sức mua hạn chế.

- Sự bất ổn, yếu kém của thị trường các yếu tố sản xuất như thị trường tài chính, đầu tư trong và ngoài nước, hoạt động của hệ thống ngân hàng...

- Các doanh nghiệp trở nên "ốm yếu", số doanh nghiệp phá sản nhiều hơn các doanh nghiệp gia nhập thị trường...

Thực tiễn phát triển kinh tế ở các nước đang phát triển nói chung, nền kinh tế Việt Nam nói riêng, theo chúng tôi nên quan niệm chu kỳ kinh tế như là một giai đoạn từ tăng trưởng suy giảm tăng trưởng - phục hồi đà tăng trưởng. Có thể hiểu sự suy giảm tăng trưởng là GDP thực tế thấp hơn sản lượng tiềm năng, nền kinh tế rơi vào suy giảm tăng trưởng với các dấu hiệu như đã trình bày ở trên. Sự suy giảm tăng trưởng có thể do tác động cả về phía tổng cầu và tổng cung. 


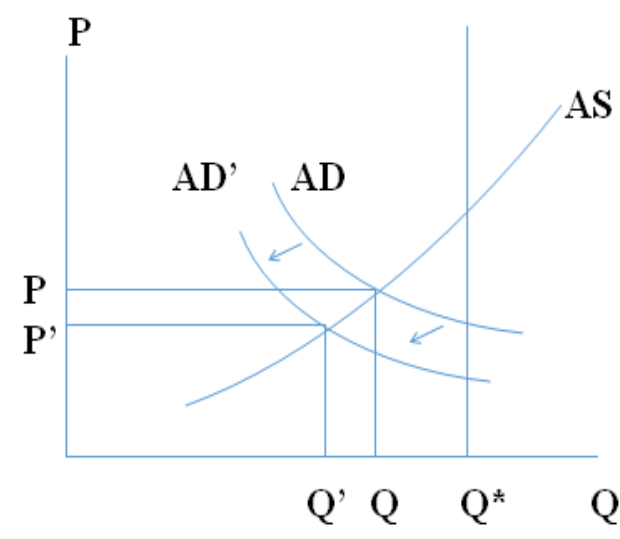

Hình 2. Kinh tế suy giảm do tổng cầu

Khi tổng cầu biến động, đường $A D$ dịch chuyển xuống $A D^{\prime}$, làm cho sản lương giảm tù̀ $Q$ xuống $Q$ ', giá giảm tì̀ $P$ tới $P^{\text {' }}$ (giảm lạm phát).

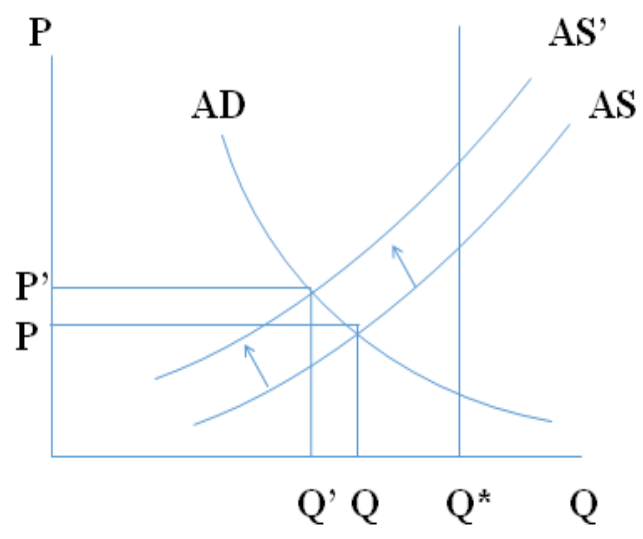

Hình 3. Kinh tế suy giảm do tổng cung

Do có sụ đột biến tù phía cung, tổng cung $A S$ dịch chuyển sang trái $A S^{\prime}$, làm cho sản lương giảm tù $Q$ xuống $Q$ ', giá cả tăng tù $P$ lên $P^{\prime}$ (lạm phát tăng).

Nguồn: P.A. Samuelson - W.D.Norhaus (2007); Trang 352.

Trong các lý thuyết về chu kỳ kinh tế, những người ủng hộ lý thuyết "Chu kỳ kinh doanh thực tế" đã giải thích sự biến động của chu kỳ kinh tế là do các "cú sốc công nghệ" có tác động lan tỏa tích cực hay tiêu cực đến năng suất của nền kinh tế (P.Samuelson; Trang 355). Các nhà kinh tế theo trường phái này giả định rằng, khi nền kinh tế trải qua các biến động trong khả năng chuyển các yếu tố đầu vào thành sản lượng đầu ra, sẽ gây ra những biến động trong sản lượng và việc làm. Lý thuyết này cũng giải thích rằng, giai đoạn suy thoái của chu kỳ kinh tế là do sự thụt lùi của công nghệ, theo đó làm giảm sản lượng và việc làm của nền kinh tế (N.Gregory Mankiw; 1996; Trang 404).

Những người phản đối lý thuyết "Chu kỳ kinh doanh thực tế" không tin rằng nền kinh tế phải trải qua các "cú sốc lớn về công nghệ", bởi vì "nhìn chung, tiến bộ công nghệ diễn ra từ từ" và "sự thụt lùi về công nghệ là điều đặc biệt khó hiểu" (N. Gregory Mankiw; 1996;
Trang 404). Tuy nhiên, vấn đề chúng ta quan tâm ở đây là năng lực sử dụng nguồn lực của nền kinh tế, đặc biệt là công nghệ, sẽ là nhân tố quyết định yếu tố năng suất (Productivity) trong nền kinh tế. Đây cũng là nhân tố có ảnh hưởng quyết định đến năng lực cạnh tranh và tăng trưởng bền vững của nền kinh tế.

\section{NHẬN DIỆN "ĐÁY" CHU KỲ KINH TẾ Ở VIẸTT NAM}

Từ đầu thập niên 1990 đến nay, nền kinh tế Việt Nam đã trải qua ba thời đoạn suy giảm tăng trưởng, đó là: 1998 - 1999; 2008-2009 và 2011 - 2013.

Nếu như 2 đợt suy giảm tăng trưởng trước, là do nền kinh tế Việt Nam chịu tác động mạnh từ các cuộc khủng hoảng kinh tế từ bên ngoài, thì đợt suy giảm tăng trưởng kinh tế kể từ năm 2011 chủ yếu xuất phát từ nội tại nền kinh tế, mà những yếu kém, bất cập đã được nhiều nghiên cứu chỉ rõ. 
Bảng 1. Tăng trưởng kinh tế Việt Nam (2008 - 2014)

\begin{tabular}{|l|c|c|c|c|c|c|c|}
\hline & $\mathbf{2 0 0 8}$ & $\mathbf{2 0 0 9}$ & $\mathbf{2 0 1 0}$ & $\mathbf{2 0 1 1}$ & $\mathbf{2 0 1 2}$ & $\mathbf{2 0 1 3}$ & $\mathbf{2 0 1 4}$ \\
\hline - \% GDP & 5,66 & 5,4 & 6,42 & 6,24 & 5,25 & 5,42 & 5,98 \\
- \% CPI & 19,89 & 6,52 & 11,75 & 18,58 & 9,21 & 6,04 & 1,84 \\
- I/GDP (\%) & 43,1 & 42,8 & 41,9 & 36,4 & 33,5 & 30,4 & 31,0 \\
- Bội chi & 4,60 & 6,90 & 5,60 & 4,90 & 4,80 & 5,30 & 5,30 \\
ngân sách & & & & & & & \\
(\% GDP) & & & $-12,6$ & $-9,80$ & 0,748 & 0,10 & 2,0 \\
- Cân bằng & -18 & $-12,8$ & & & & & \\
ngoại \\
thương (Tỷ
\end{tabular}

Nguồn: Tổng hợp tù Ủy ban Kinh tế của Quốc hội, 2014 (trang 4) và Thời báo Kinh tế Việt Nam (trang 6)

Bảng trên cho thấy, tốc độ tăng trưởng GDP của Việt Nam đạt tỷ lệ thấp nhất là năm 2012: 5,25\% (2011: 6,24\%), năm 2013 tăng nhẹ ở mức 5,42\% và năm 2014 đạt $5,98 \%$. Như vậy năm 2012 nền kinh tế đã "chạm đáy" của đà suy giảm và kéo dài cho đến cuối 2013, sau đó có dấu hiệu hồi phục khá rõ năm 2014.

Theo chúng tôi, để xác định nền kinh tế Việt Nam đã "chạm đáy" suy giảm tăng trưởng và bắt đầu hồi phục chưa, cần xem xét ở các tiêu chí cơ bản, cụ thể là:

Thư nhất, nếu xét về tăng trưởng GDP, “đáy” tăng trưởng ở mức 5,25\% năm 2012, mức độ hồi phục tăng trưởng của nền kinh tế diễn ra chậm và có nhiều khó khăn gắn với mục tiêu quan trọng nhất là ổn định kinh tế vĩ mô, tái cấu trúc nền kinh tế theo hướng nâng cao chất lượng tăng trưởng, hiệu quả và phát triển bền vững.

Thư hai, tình hình hoạt động của các doanh nghiệp đặc biệt là khu vực doanh nghiệp tư nhân (DNTN), mức độ chạm đáy không trùng pha với đà tăng trưởng, mà “đáy” là năm 2013, khi số doanh nghiệp dừng hoạt động và giải thể lên đến 60.737 doanh nghiệp, tăng $11,9 \%$ so với năm 2012. Đáng chú ý nữa là, vốn đăng ký mới của các doanh nghiệp năm 2013, ở mức thấp nhất trong 3 năm 2011 - 2013.

Thứ ba, trong 2 năm 2013 - 2014, kinh tế vĩ mô đã chuyển biến ngày càng ổn định, lạm phát suy giảm, các cân đối vĩ mô trong nền kinh tế tốt hơn, tuy nhiên tình trạng nợ xấu và bất ổn của hệ thống ngân hàng, tính hiệu quả trong hoạt động kinh doanh của khu vực doanh nghiệp nhà nước (DNNN), tiến độ tái cấu trúc nền kinh tế... còn hạn chế, bất cập.

Thứ $t u$, các yếu tố cung - cầu và cân đối cung - cầu trong nền kinh tế từ năm 2011 2014 vẫn tồn tại những khó khăn, bất ổn. Về phía cung, cùng với suy giảm trong sản xuất kinh doanh là tình hình hàng tồn kho trong nền kinh tế khá cao, tốc độ cải thiện tình hình chậm.Về phía cầu, cùng với sự suy giảm trong đầu tư của các doanh nghiệp trong nước, sức mua của nền kinh tế trầm lắng và tăng chậm.

Tình hình trên cho phép củng cố nhận định, kinh tế Việt Nam đã "chạm đáy" suy giảm tăng trưởng, nhưng đang đi lên (từ 2013) chậm chạp và còn tiềm ẩn rủi ro, thậm chí không loại trừ có nguy cơ mở rộng đáy suy giảm tăng trưởng 
của nền kinh tế, cho dù tốc độ phục hồi của nền kinh tế đã khá rõ rệt trong những tháng gần đây (tăng trưởng quý $\mathrm{I} / 2015$ đạt $6,03 \%$ so với cùng kỳ năm trước).

\section{4. "CĂN NGUYÊN" SUY GIẢM TĂNG TRƯỞNG CỦA NỀN KINH TẾ VIẸTT NAM}

Nguyên nhân chủ yếu của những khó khăn, bất cập và suy giảm tăng trưởng của nền kinh tế Việt Nam những năm gần đây, là do mô hình tăng trưởng kinh tế theo chiều rộng, dựa vào thâm dụng tài nguyên và vốn đã kéo dài quá lâu. Thêm vào đó tư duy điều hành chính sách còn ảnh hưởng quan điểm "Quản trị tổng cầu" để kích thích tăng trưởng, kể cả khi Trung Ương đã ban hành NQ11 (2011) về kiềm chế lạm phát, ổn định kinh tế vĩ mô, chuyển đổi mô hình tăng trưởng.

Tuy nhiên, căn nguyên và nguồn gốc của những hạn chế, bất cập của nền kinh tế, chính là do trình độ khoa học công nghệ (KHCN) còn thấp, năng suất lao động xã hội thấp, hiệu quả đầu tư của nền kinh tế có nhiều bất cập. Đây cũng chính là "gốc rễ” dẫn đến "vòng luẩn quẩn" nghèo đói, tình trạng mắc bẫy "thu nhập trung bình" ở nhiều nước đang phát triển, mà nền kinh tế Việt Nam hiện nay cũng không phải là một ngoại lệ “được miễn nhiễm” các nguy cơ này.

Theo báo cáo của Tổ chức lao động quốc tế (ILO) năm 2013, NSLĐ của Việt Nam chỉ bằng 1/4 của Thailand, 1/5 của Malaysia, 1/10 của Hàn Quốc và $1 / 15$ của Singapore (Ủy ban Kinh tế của Quốc hội; 2014; Trang 5). Còn thông tin mới nhất của tổ chức năng suất Châu Á (APO 2014) thì NSLĐ của Việt Nam năm 2012, tính theo sức mua tương đương năm 2011 đạt 7.900 USD/ người, chỉ bằng $6,9 \%$ của Singapore (114.400 USD), bằng $16,95 \%$ của Malaysia (46.600 USD), 34,5\% của Thailand (22.900 USD), 39,5\% của Indonesia (20.00 USD), $53,74 \%$ của Philippines (14.700 USD) và tương đương với Lào (7.900 USD), chỉ hơn 2 nước trong khu vực Đông Nam Á là Mianmar (6.700 USD) và Campuchia (4.600 USD).

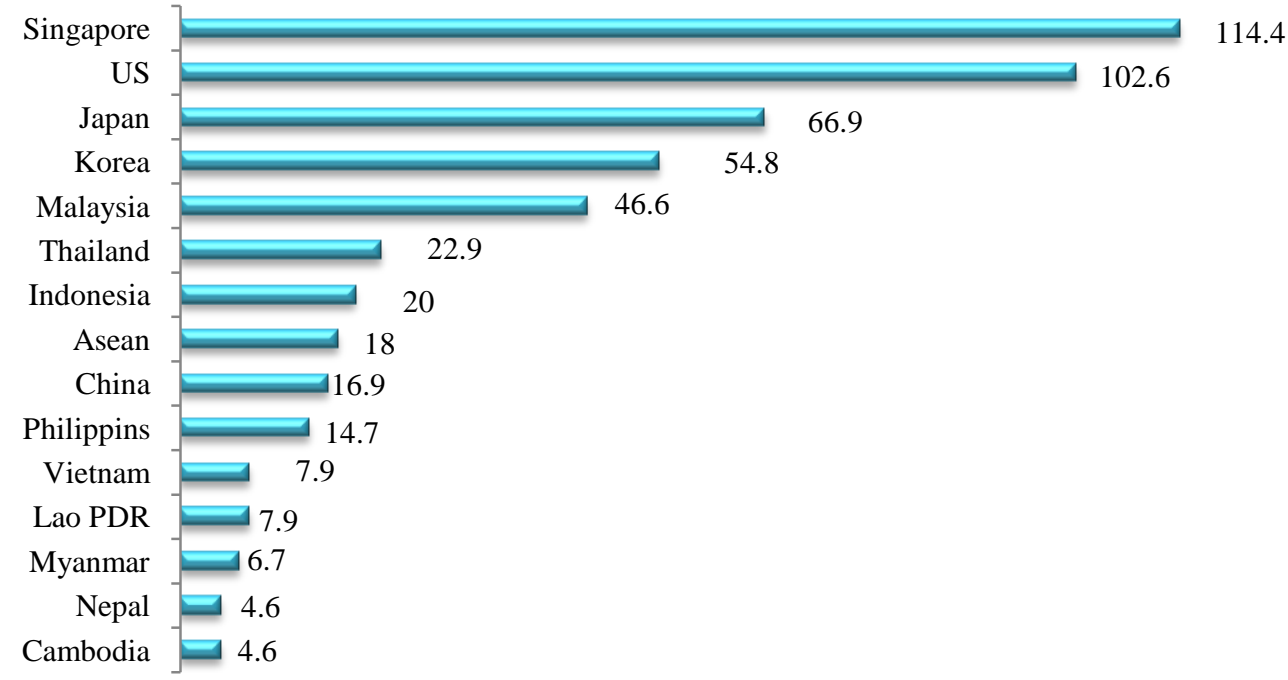

$\square$ Thousands of US dollars (as of 2012)

Hình 4. Năng suất lao động của Việt Nam so với một số quốc gia

Nguồn: APO Productivity Databook 2014; Page 67. 
Cũng theo thông tin của Tổ chức năng suất châu Á (APO, 2014), tốc độ tăng NSLĐ của Việt Nam có $\mathrm{xu}$ hướng giảm dần theo thời gian. Nếu giai đoạn 1990 - 2000 tốc độ tăng NSLĐ trung bình của Việt Nam đạt 5,7\%, đến giai đoạn 2000 - 2012 giảm xuống còn 4,5\%, trong đó giai đoạn gần đây 2005 - 2012, tốc độ tăng NSLĐ của Việt Nam chỉ còn 2,9\%.
Mặt bằng thấp về KHCN, NSLĐ ở trình độ thấp, tốc độ gia tăng NSLĐ giảm dần, đó là nguyên nhân chủ yếu dẫn đến năng lực cạnh tranh (NLCT) của nền kinh tế thấp và chậm được cải thiện, các thông tin dưới đây của World Economic Forum về chỉ số cạnh tranh toàn cầu $(\mathrm{GCI})$ ở các nước Đông Nam Á, phản ánh khá rõ tình hình này.

Bảng 2. Chỉ số cạnh tranh toàn cầu (GCI) ở các nước Đông Nam Á

\begin{tabular}{|c|l|c|c|c|c|c|c|c|}
\hline \multirow{2}{*}{ STT } & \multirow{2}{*}{ Quốc gia } & \multirow{2}{*}{$\begin{array}{c}\text { GDP bình } \\
\text { quân đầu } \\
\text { ngưòi (USD)* }\end{array}$} & \multicolumn{2}{|c|}{$\mathbf{2 0 1 1 - 2 0 1 2}$} & \multicolumn{2}{c|}{$\mathbf{2 0 1 2 - 2 0 1 3}$} & \multicolumn{2}{c|}{$\mathbf{2 0 1 3 - 2 0 1 4}$} \\
\cline { 5 - 10 } & & & Điểm/7 & $\begin{array}{c}\text { Thứ } \\
\text { hạng/142 }\end{array}$ & Điểm/7 & $\begin{array}{c}\text { Thứ } \\
\text { hạng/144 }\end{array}$ & Điểm/7 & $\begin{array}{c}\text { Thứ } \\
\text { hạng/148 }\end{array}$ \\
\hline 1 & Singapore & 51.162 & 5.6 & 02 & 5.7 & 02 & 5.6 & 02 \\
\hline 2 & Malaysia & 10.304 & 5.1 & 21 & 5.1 & 25 & 5.0 & 24 \\
\hline 3 & Brunei & 41.703 & 4.8 & 28 & 4.9 & 28 & 4.9 & 26 \\
\hline 4 & Thailand & 5.678 & 4.5 & 39 & 4.5 & 38 & 4.5 & 37 \\
\hline 5 & Indonesia & 3.592 & 4.4 & 46 & 4.4 & 50 & 4.5 & 38 \\
\hline 6 & Philippines & 2.614 & 4.1 & 75 & 4.2 & 65 & 4.3 & 59 \\
\hline 7 & Vietnam & 1.528 & 4.2 & 65 & 4.1 & 75 & 4.2 & 70 \\
\hline 8 & Campuchia & 934 & 3.9 & 97 & 4.0 & 85 & 4.0 & 88 \\
\hline 9 & Đông Timo & 3.730 & 3.4 & 131 & 3.3 & 136 & 3.2 & 138 \\
\hline 10 & Lào & 1.446 & - & - & - & - & 4.1 & 81 \\
\hline 11 & Mianmar & 835 & - & - & - & - & 3.2 & 139 \\
\hline
\end{tabular}

Nguồn: Tác giả tổng hợp tù :World Economic Forum: The Global Competitiveness Report 2013 - 2014.

(http://www.weforum.org/reports/global-competitiveness-report-2013-2014)

\section{CÁC GIẢI PHÁP ĐỄ NỀN KINH TÊ "VƯợT ĐÁY" VÀ TĂNG TRƯởNG BỀN VŨNG}

Những giải pháp để nền kinh tế Việt Nam khôi phục đà tăng trưởng và phát triển nhanh, bền vững đã được Đảng và Chính phủ định hướng trong các Nghị quyết của Đảng, Thông điệp của Chính phủ và nhiều kiến nghị của các chuyên gia kinh tế trong và ngoài nước. Dưới góc độ tiếp cận nguồn gốc, căn nguyên những hạn chế của nền kinh tế như đã trình bày ở các nội dung trên, chúng tôi xin đưa ra một số kiến nghị cụ thể sau:

Thứ nhất, trong điều hành chính sách vĩ mô, Chính phủ cần nhất quán quan điểm: Kích cầu để tăng trưởng hay tăng cung (sản lượng tiềm năng) để tăng trưởng bền vững? Chúng tôi cho rằng để nền kinh tế có thể đạt tốc độ tăng trưởng cao và bền vững, cần mở rộng sản lượng tiềm năng, nâng cao năng lực sản xuất, nhất là tăng cung tư liệu sản xuất, tạo điều kiện tăng năng suất lao động, nâng cao chất lượng

\section{Trang 24}


tăng trưởng của nền kinh tế. Đây cũng chính là tư tưởng của Đại hội Đảng lần thứ XI và quan điểm của Chính phủ trong việc đổi mới mô hình tăng trưởng, tái cấu trúc nền kinh tế để phát triển nhanh và bền vững.

Thư hai, để đổi mới mô hình tăng trưởng, chuyển dịch cơ cấu kinh tế theo chiều sâu, cần nâng cao hiệu quả đầu tư trong nền kinh tế, cụ thể là:

- Khu vực kinh tế nhà nước thực hiện tốt chức năng "bà đỡ", "nền tảng" của nền kinh tế bằng việc đầu tư phát triển cơ sở hạ tầng, cung cấp các dịch vụ công cần thiết đáp ứng yêu cầu phát triển của doanh nghiệp, tinh gọn và nâng cao hiệu quả hoạt động của các DNNN để các DNNN thực sự đảm nhiệm vai trò "tiên phong", "đầu đàn" trong nền kinh tế và mở rộng khả năng cạnh tranh trên thị trường quốc tế.

- Khu vực kinh tế tư nhân, bao gồm cả các doanh nghiệp trong nước và các doanh nghiệp FDI, cần nâng cao hiệu quả hoạt động kinh doanh bằng cách: (i) Lựa chọn đầu tư và mở rộng đầu tư đúng hướng, ưu tiên các lĩnh vực đầu tư theo chiều sâu, có lợi thế cạnh tranh; (ii) Doanh nghiệp phải coi đầu tư cho $\mathrm{KHCN}$ là đòn bẩy, chìa khóa để phát triển bền vững; (iii) Coi việc mở rộng thị trường ra bên ngoài trên cơ sở khai thác lợi thế cạnh tranh là yếu tố cốt Iõi cho sự thành công của mỗi doanh nghiệp; (iv) Nâng cao năng lực quản trị và tư duy chiến lược của đội ngũ doanh nhân.

Thú $b a$, để nền kinh tế phát triển nhanh và hiệu quả, điều cốt lõi là phải phát huy vai trò của $\mathrm{KHCN}$ trong nền kinh tế. Để $\mathrm{KHCN}$ thật sự trở thành động lực cho sự phát triển của nền kinh tế, cần có các giải pháp cơ bản như:

- Chiến lược phát triển KHCN quốc gia cần được hoàn chỉnh và cụ thể theo hướng: (i) Xây dựng được lộ trình phát triển $\mathrm{KHCN}$ quốc gia; (ii) Nâng cao năng lực lựa chọn $\mathrm{KHCN}$, đồng thời quan tâm đúng mức đến phát triển nền KHCN nội sinh; (iii) ưu tiên phát triển các lĩnh vực $\mathrm{CN}$ ứng dụng có chọn lọc, đồng thời quan tâm đúng mức đến các lĩnh vực nghiên cứu cơ bản, Nhà nước cần có vai trò chủ yếu trong việc đầu tư cho lĩnh vực nghiên cứu cơ bản.

- Đổi mới chính sách phát triển và quản lý KHCN, cụ thể: (i) Sắp xếp, giảm bớt bộ máy quản lý hành chính đối với KHCN, tăng các tổ chức hoạt động $\mathrm{KHCN}$ và dịch vụ $\mathrm{KHCN}$ của tư nhân; (ii) Đổi mới cơ bản cung cách đầu tư và quản lý kinh phí KHCN một cách hiệu quả; (iii) Đổi mới cách thức thu hút và chính sách tiền lương đối với đội ngũ cán bộ, chuyên gia $\mathrm{KHCN}$ theo hướng gắn với yêu cầu phát triển của đất nước và hội nhập quốc tế.

- Phát triển thị trường $\mathrm{KHCN}$, bao gồm cả các yếu tố cung và yếu tố cầu, gắn kết giữa cung và cầu trong môi trường kinh doanh năng động, hiệu quả, cụ thể là: (i) Về phía cung, các sản phẩm $\mathrm{KHCN}$ cần được đầu tư và phát triển gắn với thị trường, đáp ứng yêu cầu cạnh tranh của các doanh nghiệp, đặc biệt là cạnh tranh trên thị trường quốc tế; (ii) Về phía cầu, các doanh nghiệp cần có “thói quen" và áp lực trong việc tìm kiếm các sản phẩm mới $\mathrm{KHCN}$, để nâng cao năng lực cạnh tranh, nâng cao hiệu quả sản xuất kinh doanh; (iii) Về phía Nhà nước, các chính sách đầu tư phát triển, thuế tín dụng cần khuyến khích nền kinh tế phát triển theo chiều sâu, ứng dụng sâu rộng KHCN tiên tiến gắn với đổi mới mô hình quản trị ngày càng hiệu quả.

- Mở rộng các hình thức hợp tác, thu hút mọi sáng kiến $\mathrm{KHCN}$ cả ở trong và ngoài nước và mọi thành phần kinh tế. Các sáng kiến kỹ thuật, đổi mới công nghệ cần được Nhà nước và xã hội ủng hộ, nâng đỡ, phát triển nhằm phục vụ yêu cầu phát triển đất nước.

Thư tu, phát triển doanh nghiệp và đội ngũ doanh nhân có vai trò hết sức quan trọng đối 
với công cuộc phát triển của đất nước, bởi vì các $\mathrm{DN}$ và đội ngũ doanh nhân là nhân vật trung tâm để thực hiện mục tiêu "Dân giàu, Nước mạnh". Để có các DN mạnh, trước hết cần có các doanh nhân có năng lực kinh doanh, khả năng hội nhập vào môi trường toàn cầu và biết khai thác các giá trị nguồn lực của Việt Nam, đặc biệt là các giá trị truyền thống, văn hóa dân tộc. Đây cũng là chìa khóa tạo nên sự khác biệt của doanh nhân Việt Nam trong hội nhập quốc tế.

Thư năm, trong thời gian tới, để nền kinh tế phát triển nhanh và bền vững, giải pháp then chốt và có ý nghĩa đột phá quan trọng nhất, theo chúng tôi, đó là đẩy mạnh cải cách thể chế, tạo điều kiện cho các $\mathrm{DN}$ và người dân tham gia bình đẳng, thuận lợi và có hiệu quả vào công cuộc phát triển kinh tế - xã hội của đất nước. Đổi mới tư duy phát triển kinh tế - xã hội, hoàn thiện thể chế kinh tế thị trường định hướng XHCN ở Việt Nam hiện nay, không chỉ là yêu cầu cấp thiết để tăng trưởng kinh tế và phát triển bền vững, mà còn là sứ mệnh của Đảng ta tại Đại hội lần thứ XII sắp tới. Thể chế kinh tế thị trường định hướng XHCN mặc dù còn tiếp tục phải nghiên cứu, tìm tòi, sáng tạo, song chắc chắn thể chế này phải hướng đến mục tiêu "Dân giàu, nước mạnh, xã hội dân chủ, công bằng, văn minh"; đó phải là một thể chế kinh tế có khả năng dung hợp, thể chế này "cho phép và khuyến khích sự tham gia của đại đa số dân chúng vào các hoạt động kinh tế, sử dụng tốt nhất tài năng và trình độ của họ, và giúp các cá nhân thực hiện những lựa chọn họ muốn" (Daron Acemoglu \& James A. Robinson, 2013).

\section{KẾT LUẬN}

Kinh tế Việt Nam đã chạm đáy tăng trưởng vào năm 2012 và đã có dấu hiệu hồi phục từ cuối năm 2013 đến nay. Dự báo năm 2015, nền kinh tế Việt Nam tiếp tục phục hồi và chỉ có thể lấy được đà tăng trưởng khả quan từ năm 2016 trở đi, nếu nền kinh tế có những cải cách sâu rộng hơn và môi trường kinh tế thế giới ổn định. Dù lạc quan hay thận trọng, thì giải pháp cốt lõi đối với nền kinh tế Việt Nam trong thời gian tới là phải đổi mới mô hình tăng trưởng dựa trên năng suất và hiệu quả, nâng cao năng lực cạnh tranh. Nhân tố quyết định để thực hiện mục tiêu này là phải có nỗ lực chung của cả các doanh nghiệp và Chính phủ trong việc phát triển khoa học công nghệ, đưa khoa học công nghệ thực sự là động lực mạnh mẽ trong phát triển kinh tế của đất nước, đẩy nhanh quá trình $\mathrm{CNH}, \mathrm{HĐH}$ đưa Việt Nam sớm trở thành nước công nghiệp theo hướng hiện đại.

\section{TÀI LIỆU THAM KHẢO}

[1]. Nguyễn Tấn Dũng (2014). Báo cáo của Thủ tướng về tình hình kinh tế - xã hội tại kỳ họp thứ 8, Quốc hội khóa XIII http://www.chinhphu.vn/portal/page/porta l/chinhphu/noidungtinhhinhthuchien?cate goryId $=100003029$ \&articleId $=10053663$.

[2]. Daron Acemoglu \& James A. Robinson (2013): Tại sao các quốc gia thất bại. NXB Trẻ; Trang 108.
[3]. Nguyễn Chí Hải (2014): Nâng cao năng lực cạnh tranh - Yêu cầu cấp thiết đối với nền kinh tế Việt Nam hiện nay. Tạp chí Phát triển Nhân lục, số 04 (41); Trang 34 -37 .

[4]. Paul A. Samuelson - William D.Nordhaus (2007): Kinh tế học; Tập II. NXB CTQG, Hà Nội.

[5]. N. Gregory Mankiw (2006): Kinh tế vĩ $m o ̂$. NXB Thống kê, Hà Nội. 
[6]. Ủy Ban Kinh tế của Quốc hội - Viện Hàn lâm Khoa học Xã hội Việt Nam - Phòng Thương mại và Công nghiệp Việt Nam UNDP (9/2014): Diễn dàn Kinh tế Mùa Thu 2014. Tái co cấu nền kinh tế: Kỳ vọng chuyển biến mạh mẽ (Kỷ yếu Hội thảo).

[7]. Thời báo Kinh tế Việt Nam (2015): Kinh tế Việt Nam và Thế giới 2014-2015.

[8]. Trung tâm Năng suất Việt Nam (2003): Đo luờng năng suất tại doanh nghiệp. NXB Thế giới.

[9]. Chu kỳ kinh tế https://voer.edu.vn/m/chu-ky-kinhtelaab21a65.
[10]. Điểm lại cập nhật tình hình kinh tế Việt Nam.

http://wwwwds.worldbank.org/external/de fault/WDSContentServer/WDSP/IB/2014/ 12/01/000406484_20141201143505/Rend ered/PDF/928250VIETNAMEOODec0201 40Vietnamese.pdf.

[11]. APO Productivity Databook 2014 (http://www.apotokyo.org/publications/eb ooks/apoproductivity-databook-2014/

[12]. World Economic Forum: The Global Competitiveness Report 2013 - 2014.

(http://www.weforum.org/reports/globalcompetitiveness-report-2013-2014). 